\title{
EVALUATING THE COLLABORATION LEVEL AMONG PHYSICIANS IN MALAYSIAN HEALTHCARE ENVIRONMENT
}

\author{
Luma Fawaz, Jarallah $^{1^{*}}$, Masrah Azrifah Azmi Murad ${ }^{1}$, Marzanah A. Jabar ${ }^{1}$, Salfarina Abdullah ${ }^{1}$, Nurul Hidayah Ab Rahman ${ }^{2}$
}

${ }^{1}$ Faculty of Computer science and Information Technology, Universiti Putra Malaysia, Malaysia

${ }^{2}$ Faculty of Computer Science and Information Technology, Universiti Tun Hussein Onn, Johor, Malaysia

*Corresponding author email: luma-83-arb@yahoo.com

This is an open access article distributed under the Creative Commons Attribution License, which permits unrestricted use, distribution, and reproduction in any medium, provided the original work is properly cited.

\section{ARTICLE DETAILS}

Article history:

Received 07 August 2017

Accepted 11 October 2017

Available online 3 November 2017

Keywords:

healthcare, physicians

\section{ABSTRACT}

This paper explains the security and privacy requirement in Business Registration System (BRS) hosted at a government institution. These requirements will be used in an improvement for the system security and privacy requirement in BRS.

\section{INTRODUCTION}

Collaboration is an important requirement in the healthcare environments (Hospitals) to exchange information among medical researchers that can inform on critical decisions related to healthcare services. Both scientific research and medical treatment can benefit significantly from the sharing of healthcare information among different organizations. In the healthcare sector, the term "collaboration" refers to the communication which takes place among healthcare practitioners during the information and skills sharing with regards caring of a patient [1]. In healthcare sector, collaboration takes place when healthcare professionals work with one another to achieve certain goals in patient care by sharing responsibility in solving a problem and taking decisions [2]. In most developing country, there is a lack of collaboration among hospitals in sharing healthcare information. According to that, about $85 \%$ of public hospitals in Malaysia have delayed in adopting and implementing the HISs, which may negatively affect the Malaysian vision of 2020, which is to become a developed country [3]. Moreover, the collaboration which exists among physicians when they share information using HISs for the treatment of patients in hospital environments of several developing nations, is very weak. Team members' awareness with regards to their respective knowledge and skills, is increased when collaboration takes place and this further leads to improvements in decision making [4]. According to a study, a suitable communication system is needed for proper collaboration among health workers and physicians [5]. A quantitative method of enquiry was used for this study in the two public hospitals in Selangor state in Malaysia, by using questionnaire instrument. The responses received and analysed using Statistical Package for the Social Science (SPSS). The result of the analysis showed the current level of collaboration among physicians within the hospitals with regard sharing information using HIS, which was lack.

\section{THE WORK}

The main contribution of this study, is to determine the existing level of collaboration among medical staff in the healthcare environment as Malaysian context. A quantitative method of research was used for this study. Quantitative method is used this will help in obtaining observable and measurable data on the variables [6]. The quantitative method involves solving problems through a formal, objective and deductive form. The purpose of the quantitative approach was to reaffirm from the literature, the current level of collaboration among physicians in regard to sharing healthcare information. The study was conducted using the questionnaire survey. The targeted respondents for the survey were physicians with focus on the physician that works in the hospital where the records data can be obtained for the medical research from two government hospitals in Selangor state, Malaysia. The convenience sampling technique is used to select the participants demands on time and cost. The data obtained from the questionnaire survey were analysed using Descriptive analysis, Cronbach's alpha test, and Regression analysis.
Table 1: Distribution of questionnaire

\begin{tabular}{|c|c|c|c|}
\hline & Hoppinal (A) & Hoppin (B) & $\begin{array}{l}\text { Total } \\
\end{array}$ \\
\hline Dittibutod Quatiomairs & 100 & 50 & 130 \\
\hline 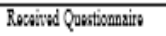 & 90 & 40 & 130 \\
\hline Complated Qustionsiro & 80 & 30 & $110(84,6 \%)$ \\
\hline Incouplat Quartiomaire & 10 & 10 & 20 \\
\hline
\end{tabular}

The Result show, the low level of collaborations types that mentioned above. This lack collaboration was mainly due the distributed and the standalone information systems. The collaboration in this case was limited to verbal and regular meeting without any sharing of data by using the system. The lack of collaboration was found to be as a result of lack of information distribution systems alongside the independent information technology support. In this study it was also found that collaboration occurred only in the form of regular verbal meetings with no form of data sharing through the use of the system. The results of the study are summarized as follows: Findings on information sharing or activities sharing between physicians of the two selected government hospitals within the state of Selangor is inconclusive due to the fact that the high ratings are weak. This can be explained by the lack of a healthcare system that is computerized and integrated thereby causing this lack collaboration in regard to the sharing information and skills for the treatment of patient inside the hospital and outside other hospitals.

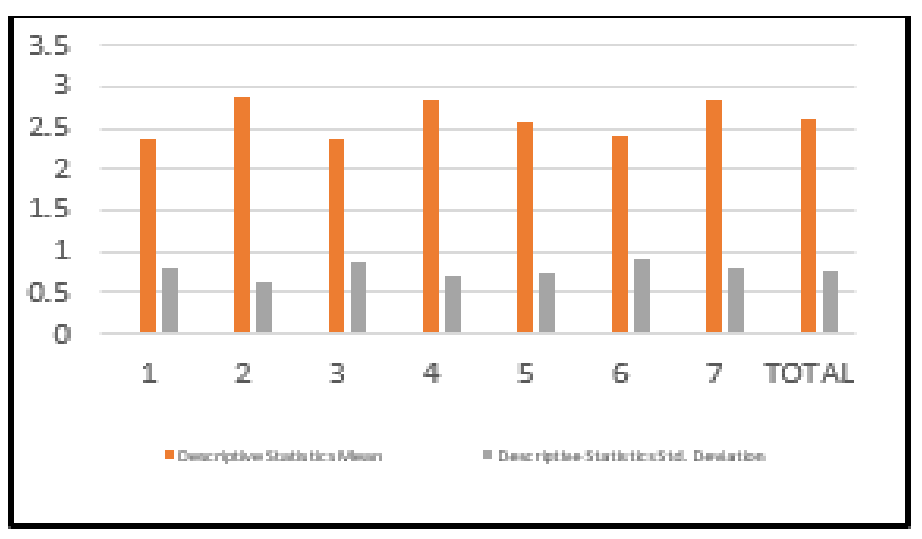

Figure 1: Mean Level of Collaboration Among Physicians

As shown in Figure 1, the mean level of collaboration among the physicians is (2.61), which is still needing to be improved. Low rating was also recorded for collaboration among physicians in terms of information sharing among hospitals for the purpose of improving medical research as 
well as medical activities. This implies the absence of an efficient information system which enhances data sharing within the hospitals and with other hospitals. Furthermore, the results imply that the real-time sharing of new activity in the hospital and with other hospitals through an information system is yet to be achieved. A number of factors are responsible for failure in effective collaboration. The first factor is having autonomous, decentralized, units, and lack of similar goals, which is common among a number of healthcare systems. Many HISs are individualized because health care systems are fragmented and lack utilizing of real-time.

Secondly, most developing countries do not adopt health care systems properly. Therefore, in the health care system of developing countries, information technologies and effective collaboration should be encouraged especially with the management administration of the healthcare $[3,7,8]$. Thirdly, because of the large number of patients, physicians work independently. Fourth, in management, the challenges of socio-technical faced by some workers in health play a role. Fifth, the acceptance and of HISs in healthcare sectors, is met by issues of security, trust, and privacy concerns play important roles. Sixth, laws and regulations allow for healthcare data sharing among different organizations', but the existing tools are not fully automated, cost-efficient, or truly real time. The distributed questionnaires among the respondents along with the number of complete and incomplete questionnaires for the two selected hospitals as shown in Table1. The reliabilities presented in Table 2 are sufficient for use because the values are higher than the reliability indicator by a researcher.

Table 2: The Scale Reliability and Consistency

\begin{tabular}{lcc}
\hline Variable & Nofltems & Cronbach's Alpha \\
\hline The collaboration among Paysicians & 7 & 0.744 \\
\hline
\end{tabular}

\section{CONCLUSION}

It was revealed by the result that collaboration among physicians in relation to share information and research findings can be facilitated by some factors which were not found in this survey of the study. Such factors are explained as follows:

a) The hospital system is not fully computerized, so the hospital uses paper to manually record patients' data which leads to incomplete patient information that cannot be managed, controlled or shared.

b) Medically staff in the hospital work independently in medical research and treatment of patient because of time factor and the unavailability of a fully electronic HIS.

c) There is a difficulty in using the existing healthcare system to acquire new knowledge from the same and different hospitals in real time by physicians.
These factors which influence physicians' collaboration in terms of sharing healthcare information using HIS should be identified. More so, this study only recommends the current level of collaboration. Some issues which should be considered by healthcare organization particularly privacy preserving of healthcare information within the hospital environment. The study also recommends how physicians' collaboration in terms of sharing accurate information, which can in turn support medical research decision and skills in patient treatment by health organizations, can be improved. More so, this paper identified the factors affecting physicians' collaboration in terms of information sharing for the purpose of health research in the selected Malaysian hospitals. However, the major challenge of e-health systems is made up of building efficient, reliable, and secure e-health platforms that are highly flexible.

\section{REFERENCES}

[1] Weir, C.R., Hammond, K.W., Embi, P.J., Efthimiadis, E.N., Thielke, S.M., Hedeen, A.N. 2011. An exploration of the impact of computerized patient documentation on clinical collaboration. International Journal of Medical Informatics, 80 (8), e62-e71.

[2] Patel, H., Pettitt, M., Wilson, J.R. 2012. Factors of collaborative working: a framework for a collaboration model. Applied Ergonomics, 43 (1), 1-26.

[3] Ahmadi, H., Nilashi, M., Ibrahim, O. 2015. Organizational decision to adopt hospital information system: An empirical investigation in the case of Malaysian public hospitals. International Journal of Medical Informatics, 84 (3), 166-188.

[4] Dunham-Taylor, J., Pinczuk, J. 2014. Introduction: Every management decision has financial implications-every financial decision has management implications. In J. Dunham-Taylor \& J. Z. Pinczuk (Eds.), Financial management for nurse managers: Merging the heart with the dollar (3rd ed.). Burlington, MA: Jones \& Bartlett Learning.

[5] Reddy, M.C., Gorman, P., Bardram, J. 2011. Special issue on Supporting Collaboration in Healthcare Settings: The Role of Informatics. International Journal of Medical Informatics, 80 (8), 541-543.

[6] Creswell, J.W. 2012. Educational research: Planning, conducting, and evaluating quantitative and qualitative research (4th ed.). Boston, MA: Pearson, 4 .

[7] Ben-Assuli, O., Leshno, M. 2016. Assessing electronic health record systems in emergency departments: Using a decision analytic Bayesian model. Health Informatics Journal, 22 (3), 712-729.

[8] Fernández-Alemán, J.L., Señor, I.C., Lozoya, P.Á., Toval, A. 2013. Security and privacy in electronic health records: a systematic literature review. Journal of Biomedical Science, 46 (3), 541-562. 